\title{
Simplified HPLC Method for the Determination of Pseudoephedrine Hydrochloride from Allegra D Tablet
}

\author{
In Chul SHIN* and Moon Hee ParK \\ Department of Pharmacology, College of Medicine, Hanyang University, \\ 17 Haengdang-Dong, Seongdong-Gu, Seoul, 133-791, Korea
}

(Received 4 June 2007; Accepted 18 June 2007)

\begin{abstract}
A sensitive, simple and highly selective liquid chromatography method of determination for extraction of pseudoephedrine hydrochloride from Allegra D tablet was developed. The chief benefit of the present method is the minimal sample preparation, as the procedure is only filtering through pore syringe filter. Two drugs (pseudoephedrine hydrochloride, fexofenadine) were separated on a $\mathrm{C}_{18}$ column and analyzed by high performance liquid chromatography (HPLC). The method had a chromatographic run time of $8.0 \mathrm{~min}$. $1 \mathrm{ml}$ of pseudoephedrine hydrochloride solution $(1 \mathrm{mg} / \mathrm{ml})$ was filtered through $0.22 \mathrm{um}$ pore syringe filter. $50 \mathrm{ul}$ of filtering solution was injected to HPLC pump and we knew the retention time $(1.85 \mathrm{~min})$ of separating of pseudoephedrine hydrochloride using UV detector at $280 \mathrm{~nm}$. We used $\mathrm{C}_{18}$ column $(4.6 \mathrm{~mm} \times 250 \mathrm{~mm})$, mobile phase solution $(<$ $0.05 \mathrm{~mol} / \mathrm{L} \mathrm{NaH}_{2} \mathrm{PO}_{4}, 2 \mathrm{ml} / \mathrm{L} \mathrm{H}_{3} \mathrm{PO}_{4}>/ \mathrm{CH}_{3} \mathrm{CN} /$ sodium dodesyl sulfate $=60 \mathrm{ml} / 40 \mathrm{ml} / 1 \mathrm{~g}$ ). We separated psedoephedrine hydrochloride at run time of $1.85 \mathrm{~min}$ from Allegra $\mathrm{D}$ tablet solution $(1 \mathrm{mg} / \mathrm{ml})$ filtered through 0.22 um pore syringe filter using UV detector at $280 \mathrm{~nm}$. Flow rate was set at $1.0 \mathrm{ml} / \mathrm{min}$ and the column temperature was set at $40^{\circ} \mathrm{C}$. Psedoephedrine hydrochloride solution $(1 \mathrm{mg} / \mathrm{ml})$ separated from Allegra D tablet was filtered through $0.22 \mathrm{um}$ pore syringe filter and injected $50 \mathrm{ul}$. We confirmed the peak of psedoephedrine hydrochloride at same retention time and the separating solution was freeze-dried. In conclusion, A simple isocratic reverse-phase HPLC method has been developed that provides excellent separation of pseudoephedrine from Allegra D tablet.
\end{abstract}

Keywords $\square$ Pseudoephedrine hydrochloride, Allegra D tablet, HPLC

\section{INTRODUCTION}

For decongestion, alpha-adrenergic agonists may be administered either orally or topically (Berkowitz et al., 2006). Oral ephedrine often causes CNS adverse effects (Nudmamud-Thanoi et al., 2006). Pseudoehedrine is a stereoisomer of ephedrine that is less potent than ephedrine in producing tachycardia, increased blood pressure and CNS stimulation (Empey and Medder, 1981; Haller and Benowitz, 2000). Pseudoehedrine has long been known to be a stable compound (Benezra and McRae, 1979) and a variety of methods have been used to analyze this active ingredient in pharmaceutical products (Gungor and Onur, 2001; Nirogi et al., 2006; Mabrouk et al., 2006; Senturk et al., 2002; Sun et al., 2005; Tan et al., 2006; Wu et al., 2006). The only known degradation product of pseudoephedrine is 2-(methylamino)propiophenone (MAPP). Two new

*Corresponding author

Tel: 02-2220-0651, Fax: 02-2292-6686

E-mail: icshin@hanyang.ac.kr compounds, 2-(carboxyamino)-propiophenone (CAPP) and 2formyl-2-(methylamino)-acetophenone (FMAAP) have just been identified from the degradation of pseudoephedrine in a dosage form. To the best of our knowledge, these two new compounds, CAPP and FMAAP, have never been reported. Methamphetamine is closely related chemically to amphetamine and ephedrine. Small doses have prominent central stimulant effects without significant peripheral actions; somewhat larger doses increase cardiac output and produce a sustained rise in blood pressure, due mainly to cardiac stimulation. Methamphetamine is a schedule II drug under federal regulations and has high potential for abuse. Fexofenadine has high specific affinity for histamine $\mathrm{H}_{1}$-receptors. Pseudoephedrine hydrochloride, which is a sympathomimetic drug acts directly on alpha-adrenergic receptors. Extended-release of pseudoephedrine/fexofenadine tablet formulations (Allegra D tablet) have been marketed. The tablet consists of pseudoephedrine hydrochloride $120 \mathrm{mg}$ and fexofenadine $60 \mathrm{mg}$. Recently methamphetamine is prepared from pseudoephedrine unlegally. To reveal the abuse of Allegra D tablet for preparing 
of methamphetamine from pseudoephedrine, this study was performed to develop of accurate and rapid method of determination for extraction of pseudoephedrine from Allegra D tablet.

\section{MATERIALS AND METHODS}

\section{Reagents and materials}

Pseudoephedrine hydrochloride, $\mathrm{NaH}_{2} \mathrm{PO}_{4}, \mathrm{H}_{3} \mathrm{PO}_{4}, \mathrm{CH}_{3} \mathrm{CN}$, sodium dodesyl sulfate were supplied by Sigma Aldrich Company. Methanol was HPLC grade and purchased from Merck Company (Darmstadt, Germany). Other chemicals were all of analytical grade and were used as received. Water was purified by redistillation before use.

\section{Instrumentation}

A High performance liquid chromatography(HPLC) equipped with Waters 515 HPLC pump, Waters 486 UV detector and an SHISEIDO Nanospace SI-2 3023 autosampler was used for HPLC analysis. Data acquisition was performed with ds CHROM data module.

\section{Chromatographic condition}

CAPCELL PACK $\mathrm{C}_{18}$ cSG120 SS column ( $5 \mu \mathrm{m}, 250 \mathrm{~mm} \times$ $4.6 \mathrm{~mm}$ i.d., Siseido Co., Japan) was used for all of the chromatographic separations. Flow rate was set at $1.0 \mathrm{ml} / \mathrm{min}$. The mobile phase composition was $\left(0.05 \mathrm{~mol} / \mathrm{L} \mathrm{NaH}_{2} \mathrm{PO}_{4}, 2 \mathrm{ml} / \mathrm{L}\right.$ $\left.\mathrm{H}_{3} \mathrm{PO}_{4}\right) / \mathrm{CH}_{3} \mathrm{CN} /$ sodium dodesyl sulfate $=60 \mathrm{ml} / 40 \mathrm{ml} / 1 \mathrm{~g}$. We used The total period for one sample was about $5 \mathrm{~min}$. The column temperature was maintained at $40^{\circ} \mathrm{C}$. We used UV detector at $280 \mathrm{~nm}$

Psedoephedrine hydrochloride $(120 \mathrm{mg})$ was dissolved in volumetric flask and diluted $(1 \mathrm{mg} / \mathrm{ml})$. We used $\mathrm{I} \mathrm{ml}$ of this solution and injected $50 \mathrm{ul}$ filtered through $0.22 \mathrm{um}$ pore syringe filter. We knew the retention time ( $1.85 \mathrm{~min}$ ) of separating of pseudoephedrine hydrochloride. We used $\mathrm{C}_{18}$ column (4.6 $\mathrm{mm} \times 250 \mathrm{~mm})$, mobile phase solution $(<0.05 \mathrm{~mol} / \mathrm{L}$ $\mathrm{NaH}_{2} \mathrm{PO}_{4}, 2 \mathrm{ml} / \mathrm{L} \mathrm{H}_{3} \mathrm{PO}_{4}>/ \mathrm{CH}_{3} \mathrm{CN} /$ sodium dodesyl sulfate $=$ $60 \mathrm{ml} / 40 \mathrm{ml} / 1 \mathrm{~g}$ ) and UV detector at $280 \mathrm{~nm}$. Flow rate was set at $1.0 \mathrm{ml} / \mathrm{min}$ and the column temperature was set at $40^{\circ} \mathrm{C}$.

Allegra D tablet was dissolved in volumetric flask and diluted $(1 \mathrm{mg} / \mathrm{ml})$. We separated psedoephedrine hydrochloride in run time of $1.85 \mathrm{~min}$ from Allegra $\mathrm{D}$ tablet solution $(1 \mathrm{mg}$ / $\mathrm{ml}$ ) filtered through $0.22 \mathrm{um}$ pore syringe filter using UV detector at $280 \mathrm{~nm}$. We used $\mathrm{C}_{18}$ column $(4.6 \mathrm{~mm} \times 250 \mathrm{~mm})$, mobile phase solution $\left(<0.05 \mathrm{~mol} / \mathrm{L} \mathrm{NaH}_{2} \mathrm{PO}_{4}, 2 \mathrm{ml} / \mathrm{L} \mathrm{H}_{3} \mathrm{PO}_{4}>\right.$ $/ \mathrm{CH}_{3} \mathrm{CN} /$ sodium dodesyl sulfate $=60 \mathrm{ml} / 40 \mathrm{ml} / 1 \mathrm{~g}$ ). Flow rate was set at $1.0 \mathrm{ml} / \mathrm{min}$ and the column temperature was set at $40^{\circ} \mathrm{C}$.

Psedoephedrine hydrochloride solution $(1 \mathrm{mg} / \mathrm{ml})$ separated from Allegra D tablet was filtered through 0.22 um pore syringe filter and injected $50 \mathrm{ul}$. We confirmed the peak of psedoephedrine hydrochloride at same retention time and the separating solution was freeze-dried.

\section{RESULTS AND DISCUSSION}

The specificity was examined by analyzing six different samples. A typical HPLC chromatogram of a standard psedoephedrine hydrochloride is presented in Fig. 1 showing separation of standard psedoephedrine hydrochloride. Retention time of psedoephedrine hydrochloride was about $1.85 \mathrm{~min}$ and no interfering peaks were observed at this time, showing good separation. Total run time for determing one sample was within 6 min. A typical HPLC chromatogram obtained from Allegra $\mathrm{D}$ tablet was showed in Fig. 2. Retention time of psedoephedrine hydrochloride was about $1.85 \mathrm{~min}$ and no interfering peaks were observed at this time, showing good separation between peaks. Total run time for determing Allegra D tablet
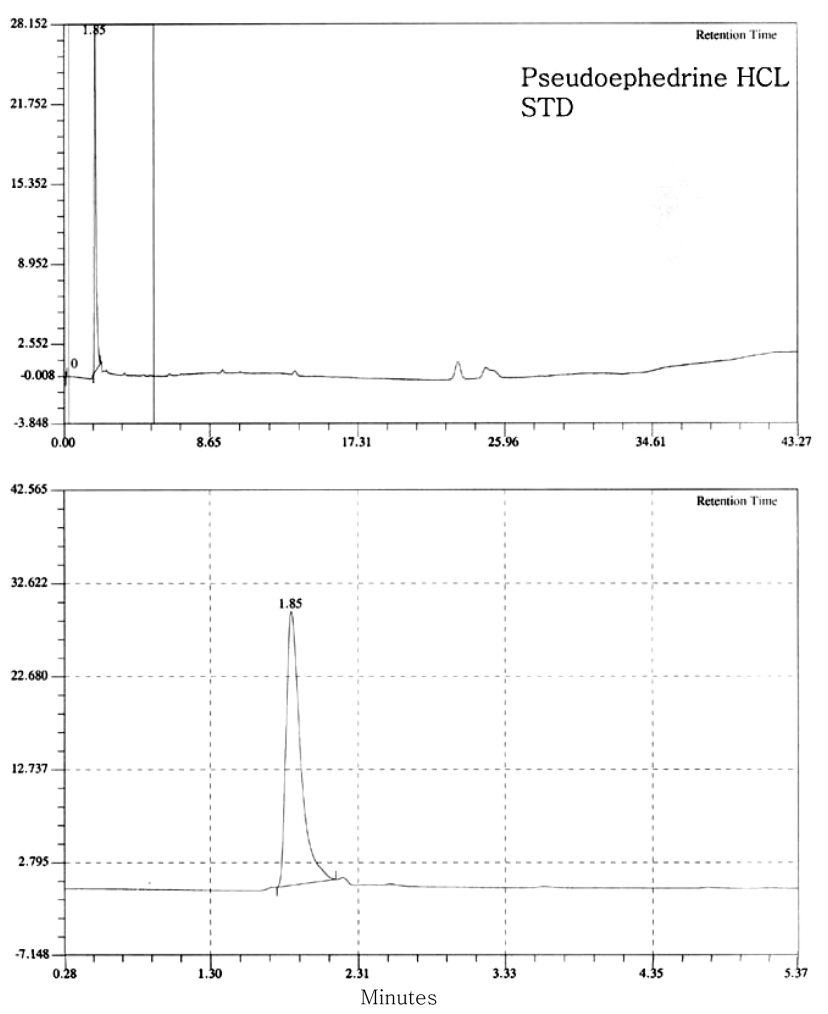

Fig. 1. HPLC chromatogram of pseudoephedrine hydrochloride. 

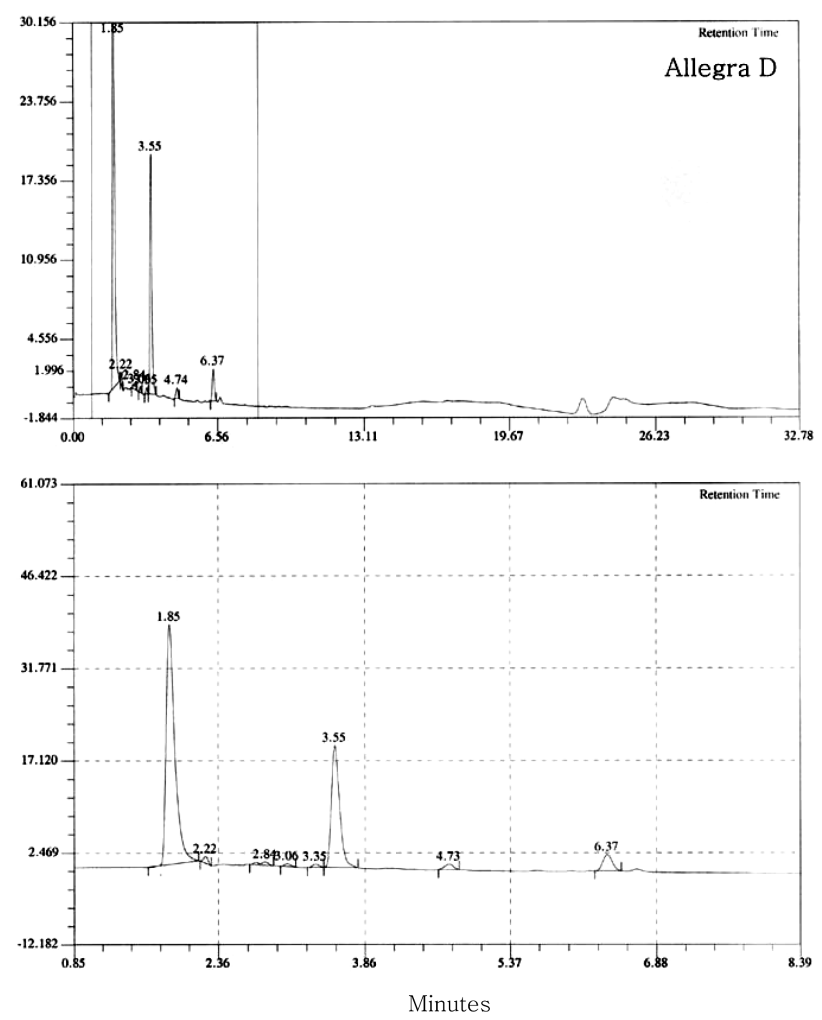

Fig. 2. HPLC chromatogram of Allegra D tablet.

was within $10 \mathrm{~min}$. Psedoephedrine hydrochloride is a very polar compound. Reducing peak tailing while maintaining peak resolution is critical for the separation. The linearity was examined in the concentration range of psedoephedrine hydrochloride. The linearity test was performed using seven different amounts of psedoephedrine hydrochloride $(1,2.5,5,10,25,50$, $100 \mathrm{ug} / \mathrm{ml})$. The correlation coefficients was 0.986 , indicating good linearity. The CAPCELL PACK $\mathrm{C}_{18}$ cSG120 SS column gave the most satisfactory results among all columns tested. Optimal conditions for separating psedoephedrine hydrochloride were obtained with a mobile phase. A mobile phase composition was $\left(0.05 \mathrm{~mol} / \mathrm{L} \mathrm{NaH}_{2} \mathrm{PO}_{4}, 2 \mathrm{ml} / \mathrm{L} \mathrm{H}_{3} \mathrm{PO}_{4}\right) / \mathrm{CH}_{3} \mathrm{CN} /$ sodium dodesyl sulfate $=60 \mathrm{ml} / 40 \mathrm{ml} / 1 \mathrm{~g}$.

The precision was examined by analyzing five different Allegra D tablet. The repeatability (within a day precision) was

Table I. Within a day and between days precision

\begin{tabular}{lc}
\hline & $\begin{array}{c}\text { pseudoephedrine hydrochloride content } \\
(\mathrm{mg} / \mathrm{tablet})\end{array}$ \\
\hline Within a day precision & $115.6 \pm 14.5$ \\
Between days precision & $111.2 \pm 20.3$ \\
\hline
\end{tabular}

Data were represented as mean \pm S.D.
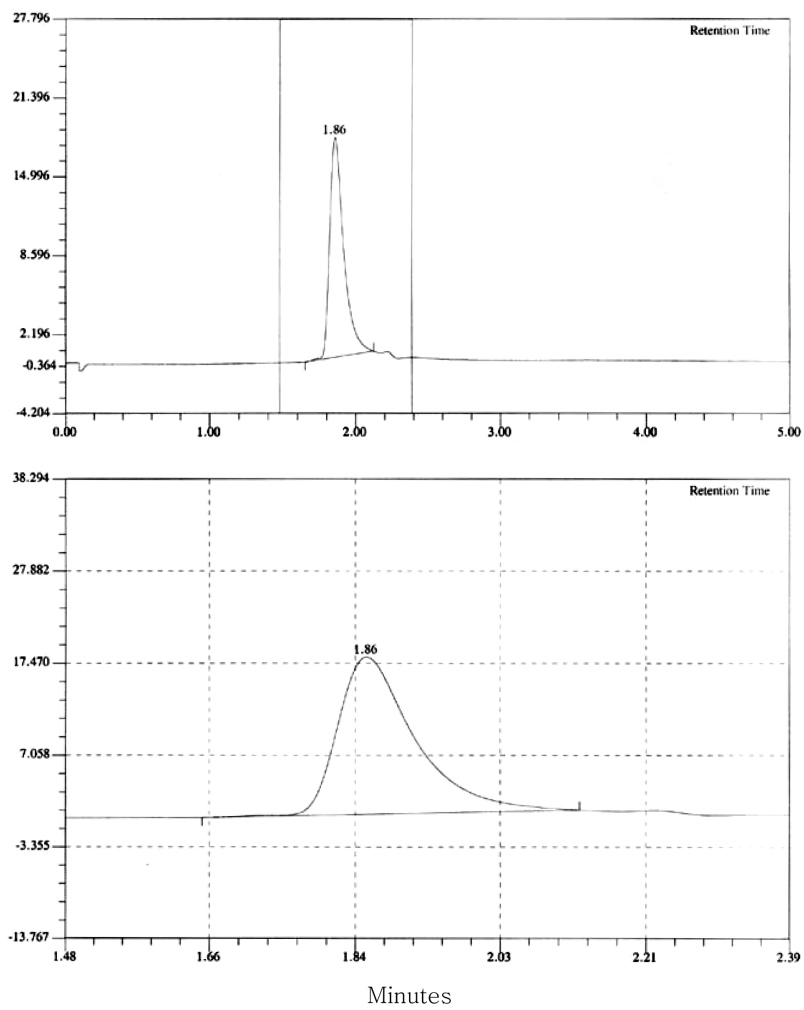

Fig. 3. HPLC chromatogram of pseudoephedrine hydrochloride extracted from Allegra D tablet.

evaluated within a day, whereas reproducibility (between days precision) was evaluated for five different days. The results obtained are shown in Table I. The accuracy was examined. Placebo samples were spiked with different amount of psedoephedrine hydrochloride $(0.1,0.5,1 \mathrm{mg} / \mathrm{ml}$; three for each one, $n=9)$ ). After this, the mixture obtained was processed according to the extraction procedure and psedoephedrine hydrochloride was determined. The mean values of the percentage recoveries obtained was $93 \pm 10.3 \%$. The lower limit of quantitation for psedoephedrine hydrochloride in human plasma was decided to be $1 \mathrm{ug} / \mathrm{ml}$. The signal to noise ratios for psedoephedrine hydrochloride peaks were larger than 3 . This data suggest that the method was suitable to determine the plasma concentrations of psedoephedrine hydrochloride.

A typical chromatogram of a sample solution of the Allegra $\mathrm{D}$ tablet is presented in Fig. 2 showing separation of psedoephedrine hydrochloride and fexofenadine hydrochloride. The CAPCELL PACK $\mathrm{C}_{18}$ cSG120 SS column gave the most satisfactory results among all columns tested. Optimal conditions for separating psedoephedrine hydrochloride were obtained with a mobile phase. A mobile phase composition was (0.05 mol/L NaH$\left.{ }_{2} \mathrm{PO}_{4}, 2 \mathrm{ml} / \mathrm{L} \mathrm{H}_{3} \mathrm{PO}_{4}\right) / \mathrm{CH}_{3} \mathrm{CN} /$ sodium dod- 
esyl sulfate $=60 \mathrm{ml} / 40 \mathrm{ml} / 1 \mathrm{~g}$.

A typical chromatogram of a sample solution of psedoephedrine hydrochloride extracted from Allegra D tablet is presented in Fig. 3 showing separation of psedoephedrine hydrochloride. The CAPCELL PACK $\mathrm{C}_{18}$ cSG120 SS column gave the most satisfactory results among all columns tested. Optimal conditions for separating psedoephedrine hydrochloride were obtained with a mobile phase. A mobile phase composition was $\left(0.05 \mathrm{~mol} / \mathrm{L} \mathrm{NaH}_{2} \mathrm{PO}_{4}, 2 \mathrm{ml} / \mathrm{L} \mathrm{H}_{3} \mathrm{PO}_{4}\right) / \mathrm{CH}_{3} \mathrm{CN} /$ sodium dodesyl sulfate $=60 \mathrm{ml} / 40 \mathrm{ml} / 1 \mathrm{~g}$.

In conclusion, A simple isocratic reverse-phase HPLC method has been developed that provides excellent separation of pseudoephedrine from Allegra D tablet.

\section{REFERENCES}

Benezra, S. A. and McRae, J. W. (1979). In: Analytical Profile of Drug Substances 8, Academic Press, Burlington, MA pp. 489507.

Berkowitz, R. B., McCafferty, F., Lutz, C., Bazelmans, D., Godfrey, P., Meeves, S., Liao, Y. and Georges, G. (2006). Onset of action of fexofenadine hydrochloride $60 \mathrm{mg} /$ pseudoephedrine hydrochloride $120 \mathrm{mg}$ in subjects aged 12 years with moderate to severe seasonal allergic rhinitis: a pooled analysis of two single-dose, randomized, double-blind, placebo-controlled allergen exposure unit studies. Clin Ther 28, 1658-1669.

Empey, D. W. and Medder, K. T. (1981). Nasal decongestants. Drugs. 21, 438-443.

Gungor, S, and Onur, F. (2001). Determination of astemizole in pharmaceutical preparations using spectrophotometric methods. J Pharm Biomed Anal 25, 511-521.

Haller, C. A. and Benowitz, N. L. (2000). Adverse cardiovascular and central nervous system events associated with dietary supplements containing ephedra alkaloids. $N$ Engl $J$ Med 21, 1833-1838.

Mabrouk, M. M., el-Fatary, H. M., Hammad, S., Wahbi, A. A. (2003). Simultaneous determination of loratadine and pseudoephedrine sulfate in pharmaceutical formulation by RP-LC and derivative spectrophotometry. J Pharm Biomed Anal 24, 597-604

Nirogi, R. V., Kandikere, V. N., Shukla, M., Mudigonda, K., Maurya, S. and Komarneni, P. (2006). Simultaneous quantification of fexofenadine and pseudoephedrine in human plasma by liquid chromatography/tandem mass spectrometry with electrospray ionization: method development, validation and application to a clinical study. Rapid Commun Mass Spectrom 20, 3030-3038.

Nudmamud-Thanoi, S., Thanoi, S. and Sobhon, P. (2006). Increase of glutamate/N-methyl-D-aspartate receptor immunodensity in the dentate gyrus of rats following pseudoephedrine administration. Neurotoxicology 27, 623-627.

Senturk, Z., Erk, N., Ozkan, S. A., Akay, C. and Cevheroglu, S. (2002). Determination of theophylline and ephedrine HCL in tablets by ratio-spectra derivative spectrophotometry and LC. $J$ Pharm Biomed Anal. 20, 291-298.

Sun, J., Wang, G., Wang, W., Zhao, S., Gu, Y., Zhang, J., Huang, M., Shao, F., Li, H., Zhang, Q. and Xie, H. (2005). Simultaneous determination of loratadine and pseudoephedrine sulfate in human plasma by liquid chromatography-electrospray mass spectrometry for pharmacokinetic studies. J Pharm Biomed Anal. 2005 39, 217-224.

Tan, Z. R., Ouyang, D. S., Zhou, G., Wang, L. S., Li, Z., Wang, D. and Zhou, H. H. (2006). Sensitive bioassay for the simultaneous determination of pseudoephedrine and cetirizine in human plasma by liquid-chromatography-ion trap spectrometry. J Pharm Biomed Anal 42, 207-212.

Wu, N., Feng, W., Lin, E., Chen, G., Patel, J., Chan, T. M. and Pramanik, B. (2002). Quantitative and structural determination of pseudoephedrine sulfate and its related compounds in pharmaceutical preparations using high-performance liquid chromatography. J Pharm Biomed Anal. 7, 1143-1155. 